\title{
Сверхкомпактный электронно-оптический модулятор на основе гибридного плазмонного волновода и слоя проводящего оксида
}

\author{
$\underline{\text { И.А. Пшеничнюк }}^{1, *}$, С.С. Косолобов ${ }^{1}$, А.И. Маймистов ${ }^{2}$, В.П. Драчев ${ }^{1,3}$ \\ ${ }^{1}$ Сколтех, Москва \\ ${ }^{2}$ МИФИ, Москва \\ ${ }^{3}$ Университет Северного Техаса, США \\ *E-mail: i.pshenichnyuk@skoltech.ru
}

DOI:10.31868/RFL2018.27

Компактное устройство, осуществляющее модуляцию оптического сигнала электрическим, является одним из ключевых элементов нанофотоники. Использование плазмонов и современных оптически активных материалов предоставляет возможность элегантного решения задачи создания такого устройства. В нашей работе представлен дизайн и рассчитаны характеристики наноразмерного электронно-оптического модулятора. В основе принципа модуляции лежит способность прозрачных проводящих оксидов (таких, например, как оксид индия-олова) изменять оптические свойства под действием электрического поля. Высокая эффективность модуляции достигается за счет гибридизации волноводной моды (несущей оптический сигнал) и плазмонной моды, создаваемой непосредственно в области модуляции. Для плазмонной моды характерна высокая степень локализации в пространстве, что значительно увеличивает эффективность работы активного слоя проводящего оксида в качестве переключателя. В предлагаемой модели устройства используются (насколько нам известно, впервые в данном контексте) плазмонные моды, распространяющиеся вдоль прямоугольных ребер, специально предусмотренных дизайном на границе раздела золота и оксида. Дисперсионные кривые таких мод похожи на дисперсии поверхностных плазмон-поляритонов, однако, в отличии от последних, обладают смешанным состоянием поляризации. Эта особенность позволяет модулятору работать с оптическими сигналами произвольной поляризации, в противовес модулятору на поверхностных плазмонах, работающему лишь со светом, поляризованным перпендикулярно слою проводящего оксида. Для оптимизации параметров устройства и расчета его характеристик численно решается система уравнений Максвелла в пространстве частот (моделирование прохождения света через модулятор), а также динамическая система полупроводниковых уравнений дрейфа-диффузии (расчет процесса переноса зарядов в модулирующем сэндвиче под действием приложенного напряжения). Громоздкие трехмерные расчеты выполнены с использованием высокопроизводительного компьютерного кластера. При разработке дизайна модулятора, помимо компактности, быстродействия и энергопотребления, значительное внимание было уделено простоте экспериментальной реализации устройства.

Работа поддержана Министерством Образования и Науки Российской Федерации, проект RFMEFI58117X0026. 